\title{
Portal hypertension: monocentric retrospective study of 387 cases and review of the literature
}

\begin{abstract}
The portal hypertension is one of the major complications of cirrhosis. It causes hemorrhages by rupture of oesophageal varices and contributes to the development of ascites and hepatic encephalopathy. This is a retrospective study collecting 387 cases of portal hypertension diagnosed at the service of Hepato-gastroenterology of Mohamed VI University Hospital of Marrakech between January 2014 and December 2018. The purpose of this work is to determine the epidemiological aspects, clinico -biological, radiological, endoscopic and therapeutic of portal hypertension and its complications. The average age was 51.3years, the sex ratio $\mathrm{M} / \mathrm{F}$ was 0.8 . Portal hypertension was revealed by haemorrhagic decompensation in $48.8 \%$ of cases, ascitic decompensation in $53.2 \%$ of cases, splenomegaly in $47.8 \%$ of cases, jaundice in $27.13 \%$ of cases, and hepatic encephalopathy in $8.52 \%$ of cases. Almost half of the cirrhotic patients were classified as child B. Upper digestive endoscopy objectified esophageal varices in the majority of patients, gastric varices in almost one-third of cases. Cirrhosis was the most common etiology of portal hypertension in $86.82 \%$, cirrhosis post viral was reported in $28.57 \%$ of cases. The alcoholic origin of cirrhosis was objectified in only $5.76 \%$ of cases. Nearly two-thirds of patients had ascitic decompensation, half of them haemorrhagic decompensation and $11.6 \%$ had hepatic encephalopathy. Hepatic hydrothorax was observed in $9.81 \%$ of cases, and hepatocellular carcinoma in $6.20 \%(n=24)$ of cases
\end{abstract}

Volume 12 Issue 6 - 2021

\author{
Fatiha Bellouhou,' Fatima Ezzahra Haddar,' \\ Adil Ait Errami,' Sofia Oubaha, ${ }^{2}$ Zouhour \\ Samlani,' Khadija Krati' \\ 'Department of Physiology, Cadi Ayyad University, Morocco \\ ${ }^{2}$ Department of Gastroenterology, Mohammed VI University \\ Hospital, Morocco
}

\section{Correspondence: Fatiha Bellouhou, Gastroenterology Department, Mohammed VI University Hospital, Marrakech, Avenue Ibn Sina Amerchich, 40000 Marrakech Morocco,} Tel +2I2634666508, Email fatihabellouhoul @gmail.com

Received: January 08, 2021 | Published: November 19, 2021

Keywords: portal hypertension, haemorrhage by rupture of oesophageal varices, ascites, hepatic encephalopathy, hepatic cirrhosis

\section{Introduction}

Portal hypertension is one of the major complications of cirrhosis It causes hemorrhages by rupture of oesophageal varices and contributes to the development of ascites and hepatic encephalopathy. The severity of these complications is inseparable from the severity of cirrhosis reflected by the degree of hepatocellular insufficiency. In Morocco, the prevalence and incidence of Portal hypertension remains unknown.

Most of the studies have been devoted to the study of cirrhosis, portal thrombosis and hepatocellular carcinoma without making it possible to specify the place of these pathologies among the causes of portal hypertension.

In order to improve the diagnosis and management of portal hypertension cases, we proposed to establish the epidemiological, clinical, para-clinical, etiological and evolutionary profiles of this condition in the hepato gastroenterology department in Marrakech university hospital center Mohamed VI.

\section{Patients and methods}

It is a retrospective study collecting 387 cases of portal hypertension diagnosed at the department of Hepato-gastroenterology of the Mohamed VI University Hospital of Marrakech between January 2014 and December 2018. The study was based on the analysis of all the files of the patients having at least one clinical, endoscopic or radiological sign of portal hypertension.

\section{Results}

In our study, three hundred and eighty seven patients were collected. The average age of our patients was 51.3 years \pm 16.31 with extremes ranging from 17 to 90 years. The majority age group is between 50 and 59years old with a sex ratio of 0.8 (Figure 1). The majority of patients report having a low socio-economic level, while only $38.24 \%$ of average socio-economic level and no high-level patient.

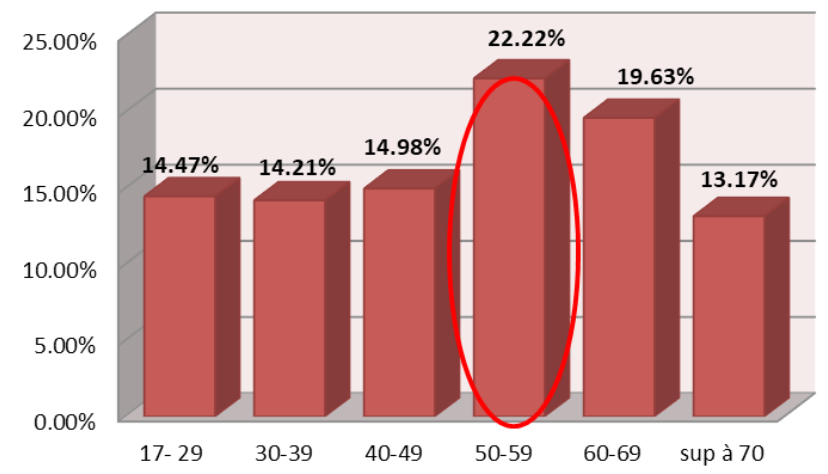

Figure I Distribution of our patients by age group.

Most patients were from urban areas, while $25.06 \%$ came from rural areas. Two hundred and sixty-two patients had risk factors of viral transmission $(67.70 \%)$ dominated mainly by informal dental care. As for toxic habits, $21.1 \%$ of patients reported being active smokers.

The delay of progression of the disease in our study was between 2 days and 3 years with an average of 12 weeks. Gastrointestinal bleeding was the most common reason for consultation in our study in $49.09 \%$ of cases $(n=190)$. Abdominal pain was reported in 108 patients $(27.09 \%)$.Portal hypertension was fortuitously found in $3.87 \%$ of cases $(n=15)$ (intraoperative, during a biological or radiological assessment). Eighty-one percent of our patients were anemic (less than $11.5 \mathrm{~g} / \mathrm{l}$ in women and $12.5 \mathrm{~g} / \mathrm{l}$ in men), $77.74 \%$ had thrombocytopenia $(<150000)$, while $43.51 \%$ had leukopenia $(<4000)$ (Table 1). 
Table I Results of the biological assessment of our patients

\begin{tabular}{|c|c|c|c|c|c|c|}
\hline \multicolumn{2}{|c|}{ Paramètres biologiques } & \multirow{2}{*}{$\begin{array}{l}\text { n } \\
331\end{array}$} & \multirow{2}{*}{$\begin{array}{l}\text { Moyenne } \\
38.50\end{array}$} & \multirow{2}{*}{$\frac{\max }{514}$} & \multirow{2}{*}{$\begin{array}{l}\min \\
5\end{array}$} & \multirow{2}{*}{$\begin{array}{l}\text { Ecart type } \\
34.39\end{array}$} \\
\hline & ALAT (UI/I) & & & & & \\
\hline & ASAT (UI/I) & 331 & 62.27 & 994 & 5 & 59.46 \\
\hline & PAL (UI/l) & 270 & 168.03 & $|74|$ & 2.6 & I 54.23 \\
\hline & GGT (UI/I) & 278 & 96.42 & 1119 & 6 & 123.3 \\
\hline & Albumine $(g / l)$ & 358 & 30.63 & 47 & 10 & 2.63 \\
\hline & BiliT (mg/l) & 340 & 21.79 & 280 & 2 & 32.69 \\
\hline & AFP (ng/ml) & 267 & 184.89 & 40000 & 0.3 & 260.96 \\
\hline & Natrémie (meq/l) & 339 & 135.82 & 158 & 115 & 5.06 \\
\hline \multirow[t]{4}{*}{ Liver function tets } & Kaliémie (meq/l) & 339 & 4.14 & 6.3 & 2.5 & 0.16 \\
\hline & Créatinine $(\mathrm{mg} / \mathrm{l})$ & 333 & 7.42 & 79 & 0.55 & 5.74 \\
\hline & Urée $(\mathrm{mg} / \mathrm{l})$ & 333 & 0.41 & 16.5 & 0.09 & 0.6 \\
\hline & $\mathrm{Hb}(\mathrm{g} / \mathrm{l})$ & 373 & 9.26 & 16.5 & 1.6 & 3.16 \\
\hline \multirow{2}{*}{ CBC } & GB $(x \mid 03 / \mathrm{mm} 3)$ & 362 & 4.92 & 36 & 0.6 & 3.60 \\
\hline & Plaquettes (x103/mm3) & 371 & 108809 & 783000 & 8000 & $920 \quad 142$ \\
\hline PT & PT (\%) & 366 & 60.76 & 100 & 13 & 18.76 \\
\hline
\end{tabular}

An abdominal ultrasound was done in $93 \%$ of cases $(n=363)$. An abdominal computed tomography scan was performed in $24.03 \%$ of patients while only $1.03 \%$ of patients had a magnetic resonance imaging (MRI) examination. Hepatic doppler was performed in $26.72 \%(n=97)$ of our patients. The flow was hepatofuge in the portal vein in $7.9 \%(n=29)$ and the speed was decreased in $61.6 \%$ of cases. The other patients had hepatopic flow with normal speed.

Eighty-one percent $(n=350)$ of our patients benefited from esophagostroduodenal fibroscopy. The abnormalities found were: oesophageal varices in $91.71 \%$ of cases, red signs in 113 patients $(32.28 \%)$, esogastroduodenal varices in $22.85 \%$ of cases and gastric varices were found in $21.42 \%$ of cases. In our series $86.82 \%$ of portal hypertension were due to cirrhosis $(\mathrm{n}=336)$ (Figure 2$)$.

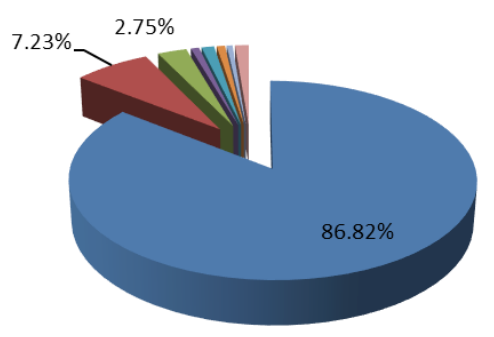

\begin{tabular}{|c|}
\hline Cirrhosis \\
\hline E Idiopathic HTP \\
\hline Chronic portal thrombosis \\
\hline Budd Chiari \\
\hline - Malignant hemopathy \\
\hline Tumor invasion \\
\hline Extrinsic compression \\
\hline $\begin{array}{l}\text { Cavernous transformation of } \\
\text { the portal }\end{array}$ \\
\hline
\end{tabular}

Figure 2 Distribution of patients according to etiologies of portal hypertension.

The etiologies of cirrhosis were: cirrhosis post viral hepatitis in $28.57 \%$ of cases, post hepatitis B in $13.98 \%(n=47)$, post hepatitis $\mathrm{C}$ in $11.60 \%(n=39)$ and viral post-infection $B$ and $C$ in $2.97 \%(n=10)$. The rest of the etiopathies of portal hypertension in our series are divided into: A portal thrombosis chronic isolated in $2.75 \%$ of cases $(n=10)$, A portal cavernoma in 5 patients (1.29\%), A budd Chiari in $1.78 \%$ (6 cases), A tumor invasion of the liver in 3 patients $(0.77 \%)$, extrinsic compression in 2 patients $(0.55 \%)$, hematological malignancies were responsible for portal hypertension in $1.19 \%(\mathrm{n}=4)$, divided between chronic myeloid leukemia in 2 patients and leukemia chronic lymphoid in 2 others (Figures 2-3).

As for the treatment, a ligation of oesophageal varices was performed in $59 \%$ of our patients, $20.86 \%(n=48)$ of them had a primary ligation, $13.47 \%(\mathrm{n}=31)$ had haemostatic ligation and 65.65 $\%$ had secondary preventive ligation $(n=151)$. The number of sessions made varies between 1 to 8 with an average of 3 sessions. A sclerosis of gastric varices was performed in $18.88 \%$ of our patients $(n=70)$ which means $93.3 \%$ of patients with gastric varices.

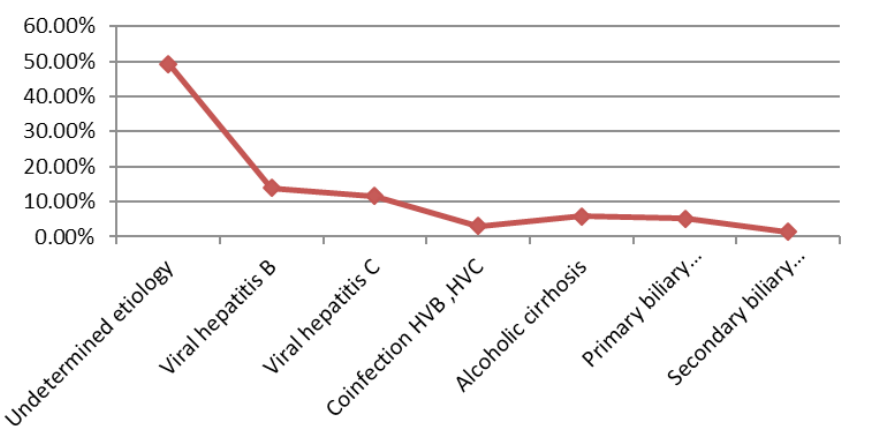

Figure 3 Distribution of cirrhotic patients according to etiologie.

In our series, $90.6 \%$ of patients had complications, $6.97 \%$ of them died.The mean duration of hospitalization was $6.5 \pm 3$ days with extremes of 2 to 15 days. The mortality was due in the majority of cases to gastrointestinal haemorrhage (37.03\%), followed by hepatocellular insufficiency at terminal stage $(29.62 \%)$. In $7.40 \%$ of cases the cause was not directly related to portal hypertension.

\section{Discussion}

Portal hypertension is defined by a pathological elevation of pressure in the venous territory of the portal system, estimated indirectly by a pressure gradient between the portal vein and the vena cava system greater than $5 \mathrm{~mm} \mathrm{Hg}$. It is due to obstacles based on the portal vein (infra-hepatic block), in the liver (intrahepatic block), or on the hepatic veins (suprahepatic block).

The etiologies of portal hypertension are numerous and variable from one country to another. Cirrhosis is the main etiology of portal hypertension in the West. It accounts for $90 \%$ of the causes of portal hypertension.In South America, the West Indies and Egypt, bilharziasis due to Schistosoma mansoni is the most common cause. ${ }^{1}$

In our series cirrhosis was the main etiology of portal hypertension in $86.82 \%$ which is consistent with data from the literature. A study in Mexico of 1486 patients with hepatic cirrhosis showed that excessive 
alcohol consumption is the leading cause of cirrhosis, followed by viral hepatitis C. ${ }^{2}$ An Italian series of 2185 cases of liver cirrhosis over a 6-month period of 79 hospitals across the country, ${ }^{83}$ found following results: viral hepatitis $\mathrm{C}$ was the first etiology of cirrhosis with $69.9 \%$ of cases, hepatitis B was found in $13 \%$ of cases, the alcoholic origin was present in $31.9 \%$ of cases.

Our results are comparable to the results reported by the other Moroccan, Tunisian, American, and Japanese studies in which liver cirrhosis was related to viral hepatitis B in $14.3 \%,{ }^{3} 12.7 \%$ to $19 \%,{ }^{4,5}$ $15 \%{ }^{6}$ and $13.9 \%{ }^{7}$ respectively. A lower rate was reported in an Italian series at $7.3 \% .^{8}$

As for the ethyl origin, the evocative biological signs are: macrocytosis, an increase in hepatic transaminases, an increase in GGT and HDL cholesterol. Some histological elements are in favor of the alcoholic origin of cirrhosis: presence of hepatocyte steatosis, presence of foci of acute alcoholic hepatitis, presence of Mallory bodies.

In our study the ethyl etiology was retained in $5.76 \%$ of patients whereas in europe it is the main cause of cirrhosis. In the United States, alcoholic cirrhosis is the second leading cause of cirrhosis in $21 \%$ after hepatitis C. ${ }^{9}$ While in Japan, ethylism accounts for $13.6 \%$ of the causes of cirrhosis placed third after viral cirrhosis B $13.9 \%{ }^{7}$

In our series, the mean age of patients was $50.1( \pm)$ 16.3years with extremes ranging from 17 to 90 years and the age group of 50 to 59 years was the most represented.This average age is comparable to that found by Londoño (52) in Spain, ${ }^{10}$ Denis Dissegnaa (55.8)in italy, ${ }^{11}$ Om k. Pathak (52) in Nepal ${ }^{12}$ and those found in Fez by M. Lahbabi ${ }^{13}$ and M. Rharnati ${ }^{14}$ at $53.6 \%$ and $52 \%$ respectively.

Portal hypertension is a condition that is often asymptomatic at first. ${ }^{15}$ This explains why it is often diagnosed at the secondary stage of complications, either with the portal hypertension itself or with the underlying hepatocellular insufficiency.

On the other hand, if the portal hypertension is moderate, the clinical diagnosis is not possible and only the taking of hepatic pressures makes it possible to identify it, the elevation of the pressure gradient being most often between 5 and $10 \mathrm{mmHg}$.Ascites was the most common decompensation event, followed by hemorrhage and jaundice and hepatic encephalopathy. ${ }^{16}$ In our series, ascites was the main mode of clinical revelation of the disease in 53\% cases made comparable to the results from the literature where the rate of ascites varies according to the studies between $55.2 \%{ }^{4}$ in Fez, 53.7\% in Tunisia, ${ }^{17} 45 \%$ in an English study ${ }^{18}$ made by Gennaro Amico collected 118 cirrhotic patients and a rate ranged from $65.5 \%$ to $71.4 \%$ according to a sub-Saharan African series. ${ }^{19,20}$ where ascites was cited as the first reason for revealing the disease.

Doppler ultrasound and possibly $\mathrm{CT}$ and magnetic resonance imaging can be used to diagnose and specify the type of portal hypertension, but the results of these methods can not be used to accurately assess the degree of portal hypertension importance.There is no correlation between the degree of portal hypertension and the portal vein diameter, but there is a negative correlation between the hepatic pressure gradient and blood flow in the portal vein. ${ }^{21}$ In our series, the flow was hepatofuge in the portal vein in $7.9 \%(\mathrm{n}=29)$ and the speed was decreased in $61.6 \%$ of cases.

A tropical series collecting 86 cirrhotic. ${ }^{22}$ reported a hepatofuge portal flow in $10.5 \%$, mixed in $7 \%$ and hepatopetus in the rest. Since the degree of portal hypertension is correlated with hepatocellular insufficiency in patients with cirrhosis, hypoalbuminaemia and prothrombin reduction have been shown to be associated with portal hypertension but uncorrelated with its degree. These biological tests therefore can not be used to evaluate the portal pressure. Other biological signs of cirrhosis, such as platelet count and prothrombin rate, signs of hypersplenism, or association of these signs have been found associated with the presence of oesophageal varices. ${ }^{23}$

The blood count is often abnormal during portal hypertension. The anomalies are multiple and frequently associated among which hypersplenism. It combines in addition to splenomegaly, thrombocytopenia usually without hemorrhagic manifestation, usually greater than $50,000 / \mathrm{mm}^{3}$, global leukopenia $(2-4 \mathrm{~g} / \mathrm{l})$ and sometimes a normally moderate anemia with a small haemolytic component of stasis. In a US study of 213 cirrhotic patients, Amir Qamar et al found that $77 \%$ of patients at the time of diagnosis had thrombocytopenia, $23.5 \%$ had leukopenia and $21.2 \%$ had anemia, the hemogram was normal in $15.9 \%$ of patients. ${ }^{24}$

In our study, $81.76 \%$ of the patients were anemic with an average hemoglobin level of $9.24 \mathrm{~g} / \mathrm{l}$, a prevalence much higher than that reported in the literature ranging between $12.6 \%$ and $21.2 \%{ }^{24,25}$ These abnormalities could be related either to hypersplenism as a consequence of HTP, or to blood spoliation during digestive haemorrhages that sometimes go unnoticed or to iron deficiency.

The presence of oesophageal or gastric varices indicates that there is severe portal hypertension. It is well established that these varicose veins can develop when the hepatic pressure gradient is equal to or greater than $10 \mathrm{mmHg},{ }^{26}$ but above this value there is no correlation between the presence and size of varicose veins and the degree of portal hypertension. The Upper endoscopy is currently the gold standard examination for oesophageal or gastric varices, but this examination is relatively invasive. Non-invasive techniques have therefore been proposed: the oesophageal video capsule and CT scan, as well as biological tests and markers of liver fibrosis.

Biological signs of cirrhosis, such as platelet counts and prothrombin levels, clinical signs such as splenomegaly, or the association of these signs have been found to be associated with oesophageal varices. ${ }^{27}$ The overall haemorrhagic risk of oesophageal varices at 2 years, without taking into account their size, is estimated at $20 \%$. This risk is maximal within two years after their diagnosis, especially during the first six months. It decreases beyond 2 years. ${ }^{28}$

A vasoactive treatment with somatostatin, terlipressin or octreotide should be started as soon as possible if there is suspicion of oesophageal varices bleeding. After haemodynamic stabilization, upper gastrointestinal endoscopy should be performed within 12 hours of patient admission. Ligation is the endoscopic treatment of reference in the event of rupture of oesophageal varices. A treatment by the injection of biological glue is recommended for gastric variceal vein rupture (GI) or gastro-esophageal varices type 2 (GOV2).

The use of TIPS was still limited by its two major complications; hepatic encephalopathy and shunt dysfunction. These drawbacks relegated TIPS to 2 nd or 3rd line treatment in the management of complications of HTP. Indeed Monescillo et al. ${ }^{29}$ showed that achieving early TIPS improved patient survival with GPHsup at 20mmhg. This joins the results of another European study. ${ }^{30}$ No patient has benefited from a TIPS in our series of cases related to the lack of centers qualified to perform this technique in Morocco.

As the etiological treatment of cirrhosis, it is fundamental, because it alone is likely to influence the natural history of the disease. 
Cirrhosis is a condition that is often not very or not symptomatic at first. There is no pathognomonic clinical sign. This is why she is mostly diagnosed at the stage of complications. In patients with cirrhosis, the complications of portal hypertension are frequent and serious. One haemorrhage by rupture of oesophageal varices occurs in more than $30 \%$ of cirrhotic patients and this proportion represents, in France, 10000 digestive haemorrhages per year. ${ }^{31,32}$

In our series the most frequent complications were ascites decompensation in $75.19 \%$ followed by haemorrhagic decompensation in 50.64\%. These results are comparable to other Maghreb and African studies. But remain high which can be related to the stage advanced in which our patients are admitted, but also to the non observance of the patients to the preventive treatment mainly related to lack of financial means.

The Child-Pugh class, active haemorrhage at endoscopy, hepatic vein pressure gradient, infection, renal failure, severity of 1 st bleeding episode, presence of portal vein thrombosis or hepatocellular carcinoma have been identified as indicators of poor prognosis. In a meta-analysis, ${ }^{33}$ the occurrence of an infection was associated with haemorrhagic recurrence and greater mortality.

In our series, intra-hospital mortality was $6.97 \%$ (27 deaths). This mortality is significantly lower than reported by Swadogo Windyam $1{ }^{19}$ who was $13.8 \%$ one week after admission, by Karoui ${ }^{34}$ where the mortality rate was $24 \%$ over a period of 30 months and by Diarra $^{35}$ with a mortality rate of $82.5 \%$ over a period of 12 months. The mortality rate of our series remains lower than the results of Amico et al which were interested in cirrhosis of different etiologies, compensated and decompensated, since they found a mortality rate of $39.9 \%{ }^{18}$

\section{Conclusion}

Portal hypertension is à Syndrome whose etiologies are varied but dominated by cirrhosis. Its major risk is the digestive haemorrhage by rupture of varicose veins requiring an emergency treatment and a prophylactic treatment. Indeed, most of these studies were focused on cirrhosis, on one of these etiologies or these complications which makes it difficult to compare the figures observed with our series, nevertheless the majority of the portal hypertension in our study were cirrhotic thus decreasing at least the risk of error that can be formed by comparing to samples that are not quite consistent with our.

\section{Conflicts of interest}

Author declares their are no conflits of interest

\section{Acknowledgments}

None.

\section{Funding}

None.

\section{References}

1. Isselbacher P, Cirrhose KJ, Harrisson TR. Principes de Médecine Interne. Paris. 1998;1341-1350.

2. Sanchez NM, Aguilar-Ramirez JR, Reyes A. Etiology of liver cirrhosis in Mexico. Ann Hepatol. 2004;3(1):30-33.

3. Abdelkrim Z. Endoscopic ligation in the secondary prophylaxis of gastrointestinal bleeding from ruptured esophageal varices (about 56 cases). Medical thesis Sidi Mohammed Ben Abdellah University. Faculty of Medicine and Pharmacy Fes. 2015.
4. Smaili R, Siai K, N. Ben Mahmoud N, et al. His profile is fast, biologic, clinical and modern with cirrhotic reviews. The 13th Journal of Gastroenterology d'Afrique Francophone \& the 15th National Congress of Gastroenterology. Mai; 2010.

5. Susana Lopez. Etiology of liver cirrhosis: an histological apraisal. Gastroenterol Clin Biol. 2000.

6. Wolf DC, Ouyang A, Talavera F, et al. Cirrhosis: emedecine, medscape. 2010;28.

7. Michitaka K, Nishiguchi S, Aoyagi Y, et al. Etiology of liver cirrhosis in Japan:a nationwide survey. J Gastroenterol. 2010;45:86-94.

8. Stroffolini T. Characteristics of liver cirrhosis in Italy:results from a multicenter study. Dig Liver Dis. 2004;36(1):56-60.

9. Sylvie N, Gabriel P, Axel B. Épidémiologie et histoire naturelle de la cirrhose. La Revue du praticien, 2005;55(14);1527-1532.

10. Londoño MC, Cárdenas A, Guevara M, et al. MELD score and serum sodium in the prediction of survival of patients with cirrhosis awaiting liver transplantation. Gut. 2007;56(9):1283-1290.

11. Dissegnaa S. Morbidity and mortality after transjugular intrahepatic portosystemic shunt placement in patients with cirrhosis. Eur $J$ Gastroenterol Hepatol. 2019;31(5):626-632.

12. Pathak OK, Paudel R, Panta OB, et al. Retrospective study of the clinical profile and prognostic indicators in patients of alcoholic liver disease admitted to a tertiary care teaching hospital in Western Nepal. Saudi J Gastroenterol. 2009;15(3):171-175.

13. Lahbabi M, Mellouki I, Elyousfi M, et al. Traitement endoscopique hémostatique des varices gastriques hémorragiques. Traitement endoscopique hémostatique des varices gastriques hémorragiques. Acta Endosc. 2012;42 :98-103.

14. Taoufik R. Le profil épidémiologique de l'hypertension portale au CHU Hassan II de Fès. T

15. Friedman SL, Millward-Sadler GH, Arthur MJP. Liver fibrosis and cirrhosis. In:Millward-Sadler GH, Wright R, Arthur MJP, editors. Wright's liver and biliary disease. London: Saunders; 1992. p. 821-81.

16. Naveau S, Borotto E, Giraud V, et al. Descriptive epidemiology of patients with alcoholic liver disease hospitalized in a hepato-gastroenterology service. Gastroenterol Clin Biol. 1999;23(5):544-551.

17. R. Smaili, K. Siai, N. Ben Mahmoud, H. Elloumi, M. Ghozzi, N. El Jeridi, Mm. Azzouz. Le profil épidémiologique, Clinique et évolutif des cirrhotiques d'âge jeune.13ème Journées de Gastroentérologie d'Afrique Francophone \& 15ème Congrès National de Gastroentérologie. Mai, 2010

18. D'Amico G, Morabito A, Pagliaro L, et al. Survival and prognosis indicators in compensated and decompensated cirrhosis. Dig Dis Sci. 1986;31:468-475

19. https://beep.ird.fr/collect/uouaga/index/assoc/M13092.dir/M13092.pdf

20. Al-Nakib B, Nakib W, Bayoumi A, et al. Hepatitis B virus (HBV) markers among patients with chronic liver diseases in Kuwait. Trans $R$ Soc Trop Med Hyg. 1982;76(3):348-350.

21. Bioulac-Sage P, Le Bail B, Balabaud C. Liver and biliary tract histology. In:Bircher J, Benhamou JP, McIntyre N, Rizetto M, Rodes J editors. USA :Oxford;2015.

22. Diarra M, Konaté A, Diarra A, et al. Ultrasound contribution in the diagnosis of cirrhosis in tropical area. J Afr Hépatol. Gastroentérol. 2009;3:125-129.

23. Burak KW, Lee SS, Beck PL. Portal hypertensive gastropathy and gastric antral vascular ectasia (GAVE) syndrome. Gut. 2001;49:866-872.

24. Qamar AA, Norman D, Groszmann RJ, et al. Incidence, Prevalence and Clinical Significance of Abnormal Hematologic Indices in Compensated Cirrhosis. Clin Gastroenterol Hepatol. 2009;7(6):689-695. 
25. De Lisi S, Peralta S, Arini A, et al. Oesophagogastroduodenoscopy in patients with cirrhosis:Extending the range of detection beyond portal hypertension. Dig Liver Dis. 2011;43(1):48-53.

26. Lebrec D, de Fleury P, Rueff B, et al. Portal hypertension, size of esophageal varices and risk of gastrointestinal bleeding in alcoholic cirrhosis. Gastroenterology. 1980;79(6):1139-1144.

27. Thabut D, Moreau R, Lebrec D. Screening for esophageal varices:endoscopy, other tools, or endoscopy and other tools? Hepatology. 2008; 47(5):1434-1436.

28. De Franchis R. Updating consensus in portal hypertension :report of the Baveno III Consensus workshop on definitions, methodology and therapeutic strategies in portal hypertension. J Hepatol. 2000;33(5):846852 .

29. Monescillo A, Martinez-Lagares F, Ruiz-del_Arbol L, et al. Influence of portal hypertension and its realy decompression by TIPS placement on the outcome of variceal bleeding. Hepatology. 2004;40:793-801.
30. JC Garcia Pagan, K Caca, C Bureau, et al. Early TIPS in cirrhotic patients with variceal bleeding. N Eng J Med. 2010;362(25):2370-2379.

31. Plessier A, Condat B, Valla D. Syndrome de Budd-Chiari primitive, Sang Thrombose Vaisseaux. Urgence Vasculaire. 2004;16(6):317-321.

32. Salerno F, Borroni G, Moser P, et al. Survival and prognostic factors of cirrhotic patients with ascites:a study of 134 outpatients. Am J Gastroenterol. 1993;88(4):514-519.

33. Bernard B, Grangé JD, Nguyen Khac E, et al. Antibiotic prophylaxis for the prevention of bacterial infections in cirrhotic patients with gastrointestinal bleeding:a metaanalysis. Hepatology. 1999;29(6):1655-1661.

34. Karoui S, Hamzaoui S, Sahli F, et al. Mortalité au cours des cirrhoses:prévalence, causes et facteurs prédictifs. Tunis Med. 2002;80(1):21-25.

35. Noah D, Eloumou Bagnaka SAF, Andoulo FA, et al. Complications and prognosis of cirrhotic patients at the Douala General Hospital in Cameroon. Journal of Applied Medical Sciences. 2016;5(1):43-52. 